\title{
Consequences of Confinement Due to COVID-19 in Spain on Anxiety, Sleep and Executive Functioning of Children and Adolescents with ADHD
}

\author{
Ignasi Navarro-Soria ${ }^{1}{ }^{\mathbb{D}}$, Marta Real-Fernández ${ }^{1}$, Rocío Juárez-Ruiz de Mier ${ }^{2} \mathbb{D}^{\mathbb{D}}$, Borja Costa-López ${ }^{3}$, \\ Marta Sánchez ${ }^{4}$ and Rocío Lavigne ${ }^{2, * \mathbb{D}}$
}

1 Department of Developmental and Educational Psychology, University of Alicante, 03690 Alicante, Spain; ignasi.navarro@ua.es (I.N.-S.); mrf44@alu.ua.es (M.R.-F.)

2 Department of Developmental and Educational Psychology, University of Malaga, 29071 Malaga, Spain; Rjrm@uma.es

3 Department of Health Psychology, University of Alicante, 03690 Alicante, Spain; borja.costa@ua.es

4 Neuropsipe, Child and Adolescent Neuroscience Center, 29010 Malaga, Spain; msanchez@neuropsipe.com

* Correspondence: rlc@uma.es

\section{check for}

updates

Citation: Navarro-Soria, I.; Real-Fernández, M.; Juárez-Ruiz de

Mier, R.; Costa-López, B.; Sánchez, M.;

Lavigne, R. Consequences of

Confinement Due to COVID-19 in

Spain on Anxiety, Sleep and

Executive Functioning of Children

and Adolescents with ADHD.

Sustainability 2021, 13, 2487.

https://doi.org/10.3390/su13052487

Academic Editor: Trinidad García

Received: 14 December 2020

Accepted: 18 February 2021

Published: 25 February 2021

Publisher's Note: MDPI stays neutral with regard to jurisdictional claims in published maps and institutional affiliations.

Copyright: (C) 2021 by the authors. Licensee MDPI, Basel, Switzerland. This article is an open access article distributed under the terms and conditions of the Creative Commons Attribution (CC BY) license (https:/ / creativecommons.org/licenses/by/ $4.0 /)$.
Abstract: The outbreak and the quick expansion of SARS-CoV-2, from December 2019 to today, has forced countries around the world to resolve virus containment measures in order to slow down the contagion curve. Between these measures, the situation of lockdown, and the isolation or limitation of social contact between the citizens, there has been an unknown psychological impact. Certain groups (the elderly, children and teenagers, and the clinical population, for instance) arouse serious fears among professionals due to their greater vulnerability and ignorance regarding the short- and long-term consequences. The main purposes of this work are first of all to evaluate the consequences of the lockdown in children and teenagers diagnosed with attention deficit hyperactivity disorder (ADHD), sleep-related problems, and problems with executive functions. Secondly, we aim to compare the effects produced with respect to the previously mentioned variables with normotypic subjects; that is to say, between a group that was subject to lockdown and another group that was not confined. The findings show that the clinic confined group had high levels of state anxiety and problems with sleep and executive functions; differences could also be seen between the two groups, with the confined ADHD group being more negatively affected in all measured variables.

Keywords: COVID-19; confinement; children; adolescents; anxiety; sleep; executive functions; ADHD

\section{Introduction}

On 11 March 2020, the World Health Organization (WHO) named the public health emergency caused by COVID-19 an international pandemic. Given the rapid spread of the virus, all countries have had to take measures to protect the health and safety of their citizens, contain the spread of the virus, and strengthen the public health system [1]. Measures such as social isolation, mobility restrictions, and quarantine of the population were immediately adopted to mitigate the impact of the virus on a health, social, and economic level. In Spain, on the 14 March 2020, a state of emergency was declared, and along with it the obligation to close many workplaces, including schools at all educational levels. From then on, the entire population was to remain confined to their homes until further notice.

In Spain, the confinement lasted for more than a month and a half, with people being unable to leave their homes except for certain essential activities. It is estimated that during March 2020, more than 3 billion people were confined worldwide, and although the conditions of confinement varied from country to country, many families saw their work, economic and personal situations altered. In the case of children and adolescents, in addition to being unable to attend school, they were also deprived of social contact with 
peers and had limited physical activity [2]. The COVID-19 pandemic is one of very few social events to have had such an important impact on human psychology, especially due to the number of people affected and the influence it has had on all spheres of life [3]. All of this has led to a high level of psychological pressure on people in various countries [4,5], altering the mental health of adults, children, and adolescents and leading to changes in mood, behavior, and other daily habits, which may put the mental health of many people at risk both now and in the not-too-distant future [4,6-14]. The pandemic and confinement has affected people of all characteristics; however, a specifically vulnerable group are children and adolescents with neurodevelopmental disorders such as Attention Deficit Hyperactivity Disorder (ADHD), and it is to be expected that the effects of confinement on their mental health will be more intense. The emotional stress that this situation generates has neurobiological consequences that increase the probability of exacerbating concomitant diseases and vulnerability to meeting the criteria for mental disorders such as anxiety disorders, depression, sleep disorders, and acute stress [4,12,15-18], among others.

The symptoms of ADHD are related to the executive deficit associated with neurobiological dysfunctions in the frontostriatal circuits-regions that play a decisive role in higher cognitive processes [19-22]. At present, there is no clear singular definition of executive functions [23], but most authors agree that they can be described as a combination of multiple cognitive abilities that allow anticipation and the establishment of goals, the formation of plans, the initiation of activities, self-regulation, and the ability to carry plans out efficiently, making it possible for the person to control and regulate their behavior through cognitive processes $[24,25]$. Therefore, people with ADHD experience greater difficulties in terms of academic, family, and social adjustment due to these functions being crucial for adequate decision-making and interaction with the environment $[9,24-26]$.

Exposure to stress has been found to be an aggravating factor in the symptoms of the disorder [27]. A recent study conducted by Humphreys et al. [28] on 214 children with ADHD revealed that greater exposure to stressful events during early and middle childhood are associated with higher levels of ADHD symptoms in early adolescence. In addition, using neuroimaging techniques, they observed that certain brain areas had undergone potential structural changes in response to stress, increasing the symptomatology of the disorder. These results support the idea that ADHD is a heterogeneous disorder shaped by the interaction between both genetic and environmental factors [29]. Several studies have suggested that brain regions such as the prefrontal cortex ( $\mathrm{PFC})$, which has prolonged periods of maturation, may be especially vulnerable to stressful situations in early childhood [27], thus explaining the deterioration of executive, behavioral, and emotional deficits and the possible emergence of neuropsychiatric disorders in later stages [30,31]. Some studies have highlighted the fact that, following the disappearance of the stressor, cognitive difficulties are quicker to recover, whereas emotional deficits and the areas related to them, such as the amygdala, are more resistant to recovery, contributing to a higher prevalence of mood disorders in adulthood [32].

ADHD has one of the highest comorbidity rates of all neurodevelopmental disorders. Between $70 \%$ and $85 \%$ of children diagnosed meet criteria for other disorders [26], with more than $50 \%$ having three or more comorbidities $[26,33]$ and $34 \%$ of children and adolescents having anxiety disorders [28]. Studies have shown that symptoms of anxiety in ADHD often go unnoticed [34] or are confused (anticipatory concern about danger, muscle tension, sleep problems, etc.) with the nuclear symptoms of the disorder itself, thus remaining an unnoticed disorder. The unprecedented situation that children and adolescents are experiencing due to the long period of confinement as well as the threats of risk that the pandemic brings, together with their own personal and family circumstances, lead to a greater probability of the appearance of anxious and/or depressive symptoms [6,7].

Although anxiety is common in ADHD, it is not entirely clear how it influences the lives of children and young people [35]. Research with adults suggests that anxious symptoms are related to poor executive control [36], since high levels of anxiety can interfere with the ability to inhibit irrelevant information, as well as in the change of 
attentional focus between tasks. Similarly, poor attentional control can contribute to the emergence of anxious symptoms, making it difficult to inhibit irrelevant information and promoting the appearance of cognitive and emotional stress responses [37-39]. A study conducted by Jarret [40] examines the relationship between ADHD with anxious symptoms and executive deficits, developing a structural equations model that reveals greater deficits in emotional self-regulation, organization, and problem solving in the group with ADHD and anxiety when compared to subjects with ADHD on the one hand, and to subjects with anxiety, on the other.

Similar to anxiety disorders, sleep disorders are also common in children with neurodevelopmental disorders. In addition, anxiety disorders and depression have a complex, two-way relationship with sleep disorders [41]. Poor sleep can have detrimental effects on cognitive processes, behavior and mood: consequences that are exacerbated in children and adolescents with neurodevelopmental disorders such as ADHD. A multidirectional relationship exists between ADHD and sleep disorders, with some authors pointing out that sleep disturbances may exacerbate the symptoms or be the cause of them, in combination with environmental and genetic factors [42-44]. The unprecedented situation experienced during confinement by COVID-19 can be considered an environmental factor affecting sleep, with a study carried out during confinement [45] stating that the pandemic is affecting the sleep of children and adolescents. Nightmares, night terrors, difficulty falling asleep or waking up several times a night are some signs that the changes introduced in their lives are disrupting their chronobiological clock.

The National Child Traumatic Stress Network [46] state that the psychological response to COVID-19 will vary with age. In the preschool stage, manifestations of fear, loss of appetite, increased tantrums and complaints or ambivalent attachment behaviors, among others, are expected. At ages 6-12, increased rates of irritability, nightmares, sleep and appetite problems, somatic symptoms or loss of interest in peers, and excessive attachment to parents may be expected. In adolescents aged 13 to 18 years, in addition to physical symptoms, sleep or isolation problems, increased or decreased energy, higher rates of apathy or inattention to health care behaviors can be expected [47].

Given the very particular characteristics of the current health crisis, there is no doubt of the impact is it having and will have in the future on people's mental health, with certain groups such as pregnant women, the elderly, health care workers, children and adolescents, and those with a previous psychological disorder being more vulnerable and expected to suffer more due to confinement [14,46-50].

Therefore, the aim of the present study was (i) to know the consequences of confinement by COVID-19 on state anxiety, sleep, and executive functioning of a group of children and adolescents with ADHD; (ii) to examine possible differences on these consequences between a confined group of children and adolescents with ADHD and a confined group without ADHD; and secondly, to study the existing differences with a third unconfined group; (iii) to examine the possible correlations between the variables state anxiety, sleep and executive functions on a confined group of children and adolescents with ADHD and a confined non-clinical group; and (iv) to analyze the relationships between state anxiety, sleep, and executive functioning in the ADHD group including the moderating role of age and sex variables.

\section{Materials and Methods}

\subsection{Design}

The design is multimodal, since it is included different types of methodologies according to the objectives of this study. Thus, an associative-comparative and explanatory design was used to carry out this research [51].

\subsection{Participants}

The sample consisted of 234 children and adolescents, distributed in two groups: 
Confined ADHD group: Made up of 117 subjects (96 males and 20 females) who met the following inclusion criteria: to be confined due to COVID-19, to be a resident in Spain, to be between 6 and 18 years old, and to have an ADHD diagnosis prior to the confinement. The participants were between 6 and 18 years old $(\mathrm{M}=12.12$; $\mathrm{SD}=3.36)$.

Confined non-ADHD group: Made up of 117 subjects ( 58 males and 59 females) who met the following inclusion criteria: to be confined due to COVID-19, to be a resident in Spain, to be between 6 and 18 years old, and to not be diagnosed with any neurodevelopmental disorder. The participants were between 6 and 18 years old $(\mathrm{M}=12.78 ; \mathrm{DT}=2.50)$. A third unconfined group was configured from the results obtained by the samples of the implemented tests, using the data collected for the elaboration and standardization of the scales for the Spanish population.

The sample was recruited after sending the questionnaires out online, and the inclusion criteria used were: being in a situation of confinement due to the COVID-19 pandemic, being a resident in Spain, and being between the age of 6 and 18 years. The study included the collaboration of the legal guardians $(\mathrm{N}=234)$, who answered the questionnaires by asking their children, if necessary, in relation to what was observed during the period of confinement. Of these, 98 were females and 19 males aged between 33 and 68 years $(\mathrm{M}=46.26 ; \mathrm{SD}=6.36)$ in the case of the ADHD group, and 103 females and 14 males aged between 19 and 57 years $(\mathrm{M}=45.19 ; \mathrm{SD}=7.00)$ in the case of the non-ADHD group. The nationality of those surveyed was mostly Spanish $(97.4 \%$-ADHD group, $95.7 \%$-nonADHD group). In the ADHD group, $83.8 \%$ had a maternal relationship with the child or adolescent, $13.7 \%$ a paternal relationship, and the rest, with percentages ranging from $1.7 \%$ to $0.9 \%$, had other relationships as legal guardians or foster care. Finally, in the case of the non-ADHD group, the questionnaires were completed by $91.5 \%$ of mothers, $6 \%$ of fathers, and $2.6 \%$ of sisters. All legal guardians signed the informed consent, were aware of the different phases and characteristics of the study and completed the questionnaire. Those who did not complete it in its entirety or did not provide informed consent were excluded from the study.

Furthermore, other sociodemographic variables were registered. In regard to the ADHD group, $71.8 \%$ live in a space occupying between 51-99 and 100-150 square meters, compared to $73.5 \%$ in the case of the non-ADHD group. More than $98 \%$ of ADHD and non-ADHD group have not changed the residence during the lockdown. Monthly incomes exceed the interprofessional minimum wage (65\%-ADHD group, and $66.7 \%-$ non-ADHD group).

\subsection{Instruments}

The instrument, designed to be completed by parents and/or legal guardians of children and adolescents from 6 to 18 years of age, and which takes approximately 15-20 min to complete, consists of four sections that include (1) sociodemographic and health-related data, (2) state/trait anxiety in children and adolescents, (3) sleep, and (4) executive functioning. The first section was elaborated ad hoc according to the sociodemographic and health variables that are mainly related to the contextual characteristics of the minors, given the situation of confinement. The subsequent sections gather information from different standardized scales whose items have been adapted in order to be answered by the adult informants. For example, the wording of the items was adapted by modifying pronouns; for example, "You feel nervous in..." was changed to "He/She feels nervous in..."

- Ad hoc sociodemographic and clinical data questionnaire

Designed to collect information regarding sociodemographic variables such as level of education attained by informants, the monthly income of the family, the employment situation of the informant and their partner before and after the declaration of the state of alarm, employment sector to which they belong, size of the house in which they lived during quarantine, and exterior spaces which the house possess (window, balcony, terrace, patio, garden, or exterior terrain). In addition, information was collected regarding the child's mental health, as well as whether he or she was taking medication. Lastly, the ques- 
tionnaire asked whether the family unit included persons with risk factors for contracting coronavirus and whether any members had tested positive for the disease.

- $\quad$ State-Trait Anxiety Inventory for Children (STAIC) self-assessment questionnaire [52]

This questionnaire is derived from the State-Trait Anxiety Inventory (STAI) test. It evaluates anxiety as a state and as a trait, constituting two independent scales made up of 10 items each with 3 response options $(1=$ not at all, $2=$ somewhat, $3=$ very much). The scale refers to how the child feels at a given time. The state anxiety scale tries to clarify "how the child feels at a given moment", and measures transitory states of anxiety; that is, feelings of apprehension and tension and concern which fluctuate in intensity over time. Examples of items used in this scale are "your child feels calm" or "your child feels restless". It presents high reliability through Kuder Richardson's KR-20 internal consistency coefficient of 0.91 for state anxiety (Spielberger et al. [52]). Although the original implementation of the instrument is self-applicable with help of tutors or guardians if necessary, due to the special circumstances of the confinement and the telematic sending of the test, it was decided that the guardians would be the ones to complete the questionnaire, in collaboration with the child when necessary. For this, the formulation of each item was adapted as previously exemplified.

- $\quad$ BEARS sleep-screening tool for sleep disorders in childhood $[53,54]$

A brief sleep screening test made up of 9 items which analyses five main areas: bedtime problems, excessive daytime sleepiness, awakenings during the night, regularity and duration of sleep, and snoring. The aim of this test is to detect sleep disorders in children and adolescents between the ages of 2 and 18. This test was completed by parents/guardians answering questions such as "Does your child have trouble going to bed?" or "Does your child have trouble waking up in the morning, does he/she seem sleepy during the day or take naps?". Each item had 7 response options, with $1=$ totally disagree and $7=$ totally agree, even though originally a dichotomous response was used. This was decided since it is more appropriate at the methodological level and thus provides greater relativity in the type of response. Regarding reliability and internal consistency, the scale presents a Cronbach's alpha coefficient of alpha $=0.732$ [47].

- Barkley Deficits in Executive Functioning Scale-Children and Adolescents (BDEFSCA), short form [55]

This scale is completed by the child's parents/guardians and evaluates information about deficits in the executive functioning of children and adolescents (between 6 and 17 years old), in daily life activities. It is composed of 20 items with four response options to assess the frequency in which behavioral alterations occur (never, sometimes, often, and very often). It consists of items such as "your child wastes or mismanages his/her time" or "your child has trouble planning or preparing for upcoming events". Regarding the reliability and internal consistency, the short version of the scale presents a Cronbach's alpha coefficient of alpha $=0.732$. This version constitutes a screening of the extended questionnaire (70 items), both of which bring together information from different executive domains (time management, organization/problem solving, inhibition/containment, motivation, emotional regulation).

\subsection{Procedure}

A single evaluation was carried out through an online questionnaire that consisted of all the instruments described above. This format was chosen because of the situation of confinement decreed in the country. The sample, for convenience, was selected according to age, presence or not of ADHD, and being in a state of alarm for COVID-19. As previously mentioned, an unconfined population group was included in the study, using the data collected for the elaboration and standardization of the scales of the used psychometric tests. 
On Thursday, 16 April 2020 at 19:30 p.m., the questionnaire was sent and distributed through social networks and local media requesting citizen collaboration to participate in the study. The questionnaire was online for a total of two weeks.

At the beginning of the questionnaire, informed consent was required from the parents and/or legal guardians of the participants, who were informed of the anonymity of their data and the exclusive use they were to have. At the same time, the ethical principles of the Declaration of Helsinki [56] were respected.

\subsection{Ethics Committee}

This study was carried out in accordance with the Ethics Committee and Vice-Rectorate for Research and Knowledge Transfer of the University of Alicante (UA-2020-05-12).

\subsection{Statistical Analysis}

To carry out the statistical analysis, we started with the database debugging. For this purpose, an exploratory analysis was carried out, duplicated cases were eliminated, and inverse items were recoded.

A quantitative methodology was carried out, in which frequency and descriptive analyses (mean, median, and standard deviation) were applied for the socio-demographic variables (age and sex of the participants), and the variables state anxiety, sleep disorders, and executive functions, for the two confined samples. In this way, a statistical criterion was used to group the different variables into low, average, and high scores, by taking the 33.3 and 66.7 percentiles as cut-off points to find out the frequency of each group, in addition to making an expert judgement by professionals from the University of Malaga and the University of Alicante.

For the unconfined sample, mean scores have been calculated from the different scales used in previous research studies, with the aim of creating a normative reference group. These scores have been obtained from the samples that make up the test scales.

Likewise, the assumptions of linearity (scatter diagrams), normality (KolmogorovSmirnov test), independence (Gust test) and homocedasticity (Levene test) were checked in order to decide on the most suitable tests to be carried out to contrast hypotheses in the confined samples.

For the variance analysis between ADHD and non-ADHD confined groups, the nonparametric Mann-Whitney $U$ test was applied for the variables state anxiety, sleep, and executive functions since they did not meet the statistical assumptions [57]. The established confidence level was $95 \%$. Subsequently, the effect size (ES) was calculated to find out how substantial the differences between the two groups are.

Thus, an analysis of correlations between the variable state anxiety, with sleep and executive functioning was performed in both the ADHD and non-ADHD groups.

Finally, a mediation (\#1) and moderated mediation (\#2) analysis were carried out. The product-of-coefficients strategy with bootstrapping was used, applying the PROCESS macro for SPSS (IBM Corporation, New York, NY, USA) [58] to test strength and significance of the indirect effect. Bootstrapping is a non-parametric method for assessing indirect effects $[59,60]$. Bootstrapping provides the most powerful and reasonable method of obtaining confidence limits for specific indirect effects under most conditions [53]. In fact, bootstrapping overcomes several problems with non-normally distributed variables such as state anxiety, sleep, and executive functioning. Thus, for the mediation analysis (\#1, see Figure 1), the indirect effect was estimated by first regressing sleep (MedV) on state anxiety (IV), and subsequently regressing executive functioning (DV) on sleep (MedV) and state anxiety (IV). The indirect effect was then quantified as the product of the mean bootstrapped sample estimates of the regression coefficients (MedV on IV, DV on MedV controlling for IV). The standard deviation of the estimate of the indirect effect obtained over 10,000 bootstrapped resamples is the estimated standard error of the mean indirect effect, and the significance was determined based on 95\% bias-corrected confidence intervals [61]. Based on this information, bootstrap confidence intervals were generated for the indirect 
effect. A significant indirect effect via mediators between dependent and independent variables was determined if the $95 \% \mathrm{CI}$ does not contain zero.

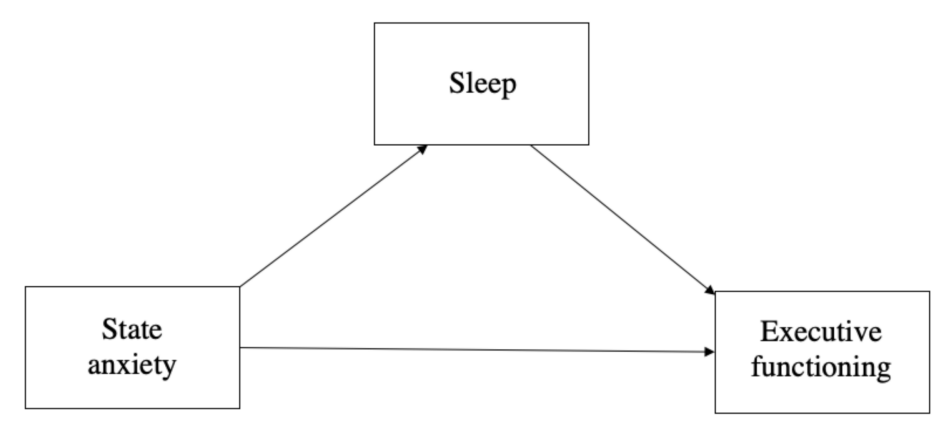

Figure 1. Conceptual mediation model (\#1).

Furthermore, in regard to the hypothesis on moderated mediation (\#2, see Figure 2), in order to test whether the indirect effect depends on age (ModV1) and sex (ModV2), coefficients were estimated independently in two regression analysis using bootstrapping. First, sleep (Me) was regressed on state anxiety (IV). Subsequently, executive functioning (DV) was regressed on sleep (MedV) and state anxiety (IV), and age and sex as moderator variables (ModV1, ModV2). An overall effect of the IV on the MedV is a necessary precondition for moderated mediation. A significant effect of age and sex (ModV1, ModV2) on executive functioning is only indicative of moderated mediation if state anxiety (IV) affects sleep $(\mathrm{MedV})$.

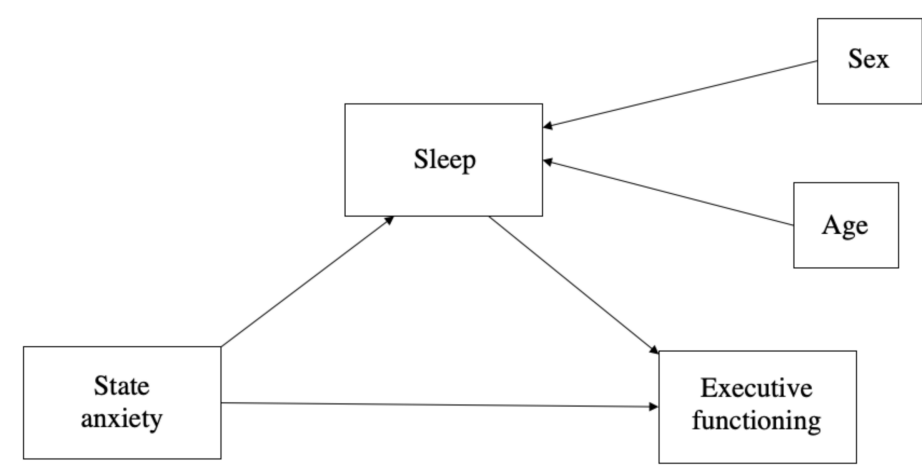

Figure 2. Conceptual moderated mediation model (\#2).

All data were analyzed using the SPSS Statistical software package, IBM SPSS Statistics v25.

\section{Results}

In order to know the consequences of confinement due to COVID-19 on state anxiety, sleep, and executive functions of a group of children and adolescents with ADHD, an analysis of frequencies and percentages was carried out, as well as a descriptive analysis of the total sample.

As can be seen in Table 1, regarding state anxiety in the confined ADHD group, $81.9 \%$ of children and adolescents show medium-high scores $(32.8 \%$ and $49.1 \%$, respectively), while $18.1 \%$ showed low scores on this test. Regarding sleep, $84.6 \%$ show mediumhigh alterations ( $35.0 \%$ and $49.6 \%$, respectively) and $15.4 \%$ low alterations. In reference to executive functioning, $91.4 \%$ of children and adolescents indicate high alterations. 
Table 1. Frequency analysis of the variables state anxiety, sleep, and executive functioning of the confined ADHD group.

\begin{tabular}{cccc}
\hline Variable & & Frequence (n) & Percentage (\%) \\
\hline State anxiety & Low & 21 & 18.1 \\
& Average & 38 & 32.8 \\
& High & 57 & 49.1 \\
Sleep & Low & 18 & 15.4 \\
& Average & 41 & 35.0 \\
EF (BDEFS-CA) & High & 58 & 49.6 \\
& Low & 10 & 8.5 \\
& Average & 22 & 18.8 \\
& High & 85 & 72.6 \\
\hline
\end{tabular}

*1 lost person.

To study possible differences between a group of children and adolescents with ADHD and a non-ADHD group in a confined situation, the Mann-Whitney non-parametric U test was carried out. As can be seen in Table 2, the results show that there are statistically significant differences between the ADHD and non-ADHD group in state anxiety $(\mathrm{U}=5340.00$; $\mathrm{z}=-2.91 ; p=0.004)$, sleep $(\mathrm{U}=5424.00 ; \mathrm{z}=-2.78 ; p=0.005)$, and executive functioning $(\mathrm{U}=2627.50 ; \mathrm{z}=-8.15 ; p=0.001)$. All these results show a higher affectation in the ADHD group with respect to the non-ADHD group, especially in executive functioning. After estimating the effect size in terms of correlation ( $r$ ), the results are considered clinically relevant in terms of the BDEFS-CA scale $(r=0.53)$ [62].

Table 2. Mann-Whitney U test for differences in anxiety, sleep, and executive functions by ADHD diagnosis.

\begin{tabular}{cccccc}
\hline Instrument & Group & Mean Rank & $\mathbf{Z}$ & $\boldsymbol{p}$ & $\mathbf{r}$ \\
\hline STAICs & ADHD & 130.36 & -2.91 & 0.004 & 0.19 \\
& Non-ADHD & 104.64 & & & 0.005 \\
BEARS & ADHD & 129.64 & 2.78 & & 0.18 \\
& Non-ADHD & 105.36 & & 0.001 & 0.53 \\
BDEFS-CA & ADHD & 153.54 & -8.15 & \\
& Non-ADHD & 81.46 & &
\end{tabular}

On the other hand, the average scores for the different scales used both for the confined ADHD and the confined non-ADHD groups were calculated and compared with the average scores derived from the test manuals, recognizing the population that makes up the sample as a normative unconfined population. When comparing the differences between the scores obtained by the unconfined sample and the non-ADHD confined sample, the latter group presents poorer scores than the unconfined group. The difference in scores is even more noticeable when comparing the results of the confined ADHD sample (see Table 3).

Table 3. Means of state anxiety, sleep, and executive functioning according to control sample, unconfined clinic, and confined clinic.

\begin{tabular}{cccc}
\hline & Total Mean (6-18 Years) & ADHD and Confinement Sample \\
& Non-Confinement Samples & $\begin{array}{c}\text { Non-ADHD and } \\
\text { Confinement Sample }\end{array}$ & 36.10 \\
\hline State Anxiety (STAIC) & 31.2 & 32.60 & 13.57 \\
Sleep (BEARS) & 7.4 & 12.60 & 80.44 \\
EF (BDEFS-CA) & 33.2 & 70.30 & (n) \\
\hline
\end{tabular}

In regard to the possible relationships between the variables and the group to which they belong (confined ADHD and non-confined ADHD), a correlation study was con- 
ducted. All correlations are considered of moderate magnitude, except for the weak correlation between state anxiety and executive functions in the group without ADHD (0.286) (see Figure 3), and the strongest correlation appearing between state anxiety and executive functions in the group with ADHD measured with the BDEFS-CA scale (0.345) (see Figure 4) [63].
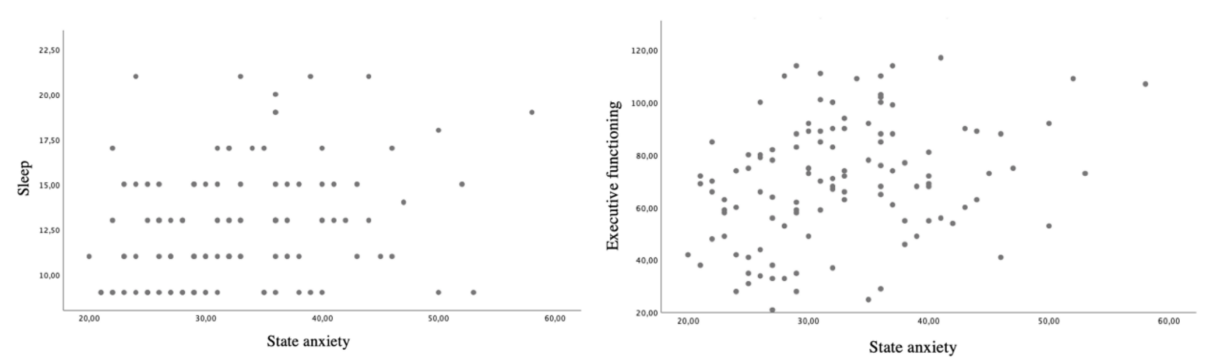

Figure 3. Correlations between sleep and state anxiety, and executive functioning and state anxiety in the group without ADHD.
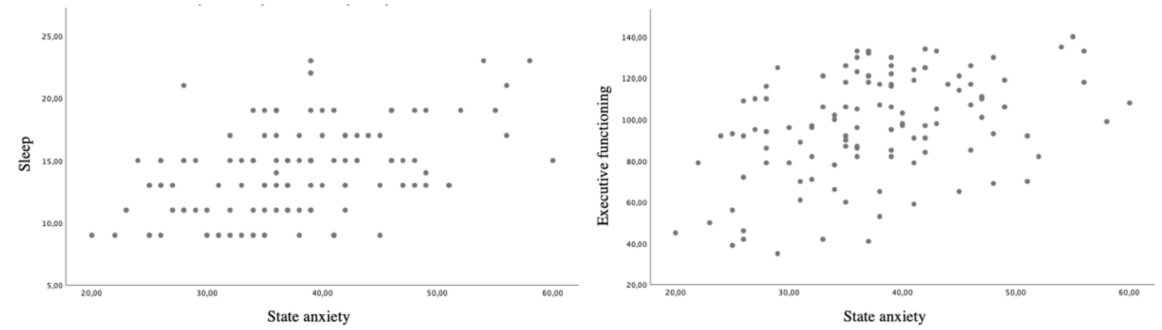

Figure 4. Correlations between sleep and state anxiety, and executive functioning and state anxiety in the group with ADHD.

Finally, in reference to the mediation analysis (\#1), the first analysis examined the indirect effect of state anxiety (IV) on executive functioning (DV) through sleep (MedV). Results revealed significant effect of the IV on the MedV (a: B $=0.19, \mathrm{SE}=04,95 \% \mathrm{CI}[0.12,0.26]$, $p=0.001)$, the MedV on the DV ( $\mathrm{b}: \mathrm{B}=1.07, \mathrm{SE}=0.37,95 \% \mathrm{CI}[0.33,1.81], p=0.005)$, and the total effect of the IV on the DV ( $\mathrm{c}: \mathrm{B}=1.07, \mathrm{SE}=0.15,95 \% \mathrm{CI}[0.78,1.37], p=0.001)$. Although the direct effect of IV on DV was significant ( $\left.c^{\prime}: B=0.87, S E=0.16,95 \% \mathrm{CI}[0.56,1.19]\right)$, there was also a significant indirect effect of the IV on the DV through the Med V $\left(a^{*} \mathrm{~b}: \mathrm{B}=0.20\right.$, $\mathrm{SE}=0.07,95 \%$ CI $[0.06,0.35]$ ) (Figure 5).

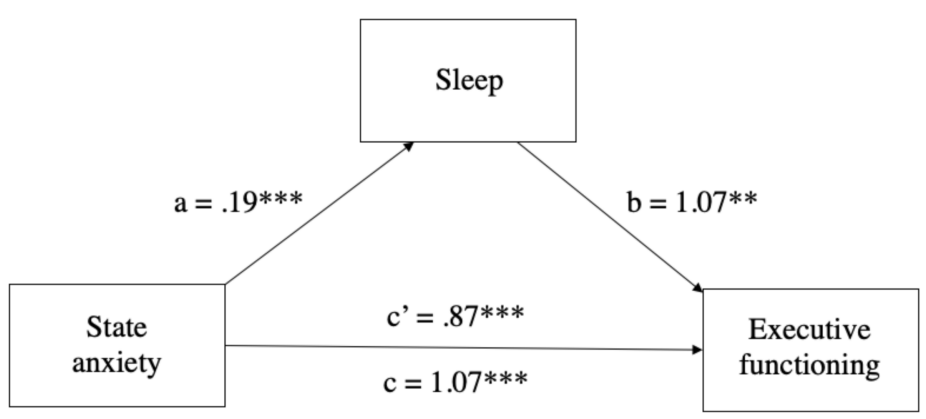

Figure 5. Results of regression analysis for mediation (\#1). Unstandardized regression coefficients. d.

However, the indexes of moderated mediation (\#2) present the association among moderators, and the indirect effect was not found to be significant $\left(\mathrm{X}^{*} \mathrm{~W}\right.$ : $\mathrm{B}_{\text {age }}=0.84$; $\mathrm{SE}=2.15,95 \% \mathrm{CI}[-3.41,5.08], p=0.7 ; \mathrm{X} * \mathrm{Z}: \mathrm{B}_{\mathrm{sex}}=3.21 ; \mathrm{SE}=3.48,95 \% \mathrm{CI}[-3.69,10.12]$, $p=0.36$ ) (Figure 6). 


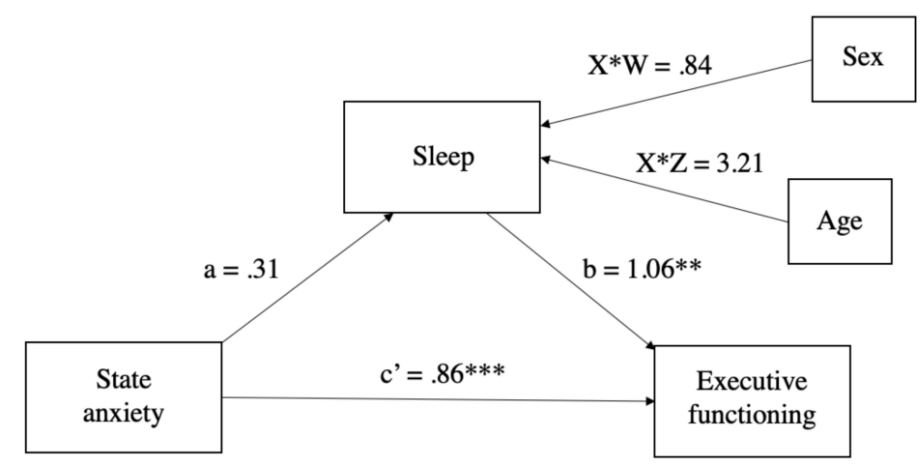

Figure 6. Results of regression analyses for moderated mediation (\#2). Unstandardized regression coefficients. Note: ${ }^{* *} p<0.01,{ }^{* * *} p<0.001$.

\section{Discussion}

The confinement due to COVID-19 has proven to be a threat to the mental health of healthy children and adolescents, so it is impossible to ignore the threat it assumes for those with a neurodevelopmental disorder such as ADHD.

The time we have lived with COVID-19 is relatively short, however there are already research groups that have evidence available on the psychological impact of the pandemic, although most studies are focused on the adult or non-pathological population [64]. Research such as that conducted by $[47,65,66]$ indicates that home confinement may have a negative impact on the physical and/or psychological well-being of children and adolescents. In a study conducted in Shanghai [67], with a sample of 241 parents of children with ADHD aged 6-15, they found that after completing questionnaires (such as SNAP-IV parent form, Child Stress Disorders Checklist, some questions related to time allocation on children's activities, mood state of the children and parents, and about attention to media coverage of the 2019-nCoV) and the analysis of the answers through logistic regression, the general mood of the children, of the parents, and the time dedicated to the study acted as significant predictors of the worsening of their children's behavior. A model of three predictors was therefore determined, with $\mathrm{F}(3,237)=31.73, p<0.001, \mathrm{R} 2=0.29$. The conclusions reached indicated that during the COVID-19 outbreak, the behavior of children with ADHD studied in Shanghai worsened significantly compared to their normal state. The negative mood of the children and their parents was associated with ADHD symptoms. In addition, the parents reported that they experienced a high level of daily stress in raising their ADHD children.

By carrying out a comprehensive and non-systematic search in seventy-seven articles with the intention of finding out the effects of the pandemic on the mental health of children and adolescents, de Miranda et al. [11] found that most of the studies analyzed have selected the anxiety and depression variable as a reference to find out the mental health status of the subject and have assessed it using different scales. Specifically, studies such as that of Chen et al. [6], conducted on a sample of 1036 children and adolescents aged 6 to 15 years, found that $18.92 \%$ showed symptoms of anxiety and $11.78 \%$ depression. To measure the presence of symptomatology, they used the SCARED screen and the DSRS-C depression self-rating scale for children, respectively. On the other hand, Xie et al. [68], in a sample of 2330 children aged 7 to 11 years, found similar values: specifically, $18.9 \%$ in anxiety symptoms measured with the SCARED screen scale and $22.6 \%$ in depressive symptoms using the CDI-S Children's depression inventory short form.

Studies such as those by Marques de Miranda et al., Cortese et al., Power et al., Lee and Xie et al. [11,17,50,69,70] have highlighted that individuals with neurodevelopmental disorders, such as ADHD, are particularly vulnerable to the distress caused by pandemic measures such as confinement, which exacerbates the manifestation of conduct problems, more challenging behaviors, increased irritability, and executive problems. 
In the light of this previous research, the present study came into existence with the intention of knowing the consequences of confinement on state anxiety, sleep, and executive functioning of a group of children and adolescents with ADHD.

After the first analysis, it was found that $81.9 \%$ of the sample had medium-high scores in state anxiety. A high level of anxiety is one of the comorbidities that often accompany ADHD. Specifically, the work of Power et al. [69] analyzed levels of anxiety in groups diagnosed with ADHD-C and ADHD-I, observing significantly higher levels in children with combined ADHD, in comparison to the group with ADHD that presented predominantly with inattention. Similarly, the study conducted by Gonzalez et al. [71], found that the ADHD-C group showed significantly higher levels in trait anxiety, compared to the ADHD-I, ADHD-HI, and control subtypes, while the ADHD-I group presented higher scores in state anxiety and symptoms that negatively affect cognitive processes (which already appear altered in the disorder itself). In a study conducted by Sadeh and Bredemier [72] it was found that high levels of trait anxiety in groups with ADHD predicted worse performance on attention tasks, increasing inattentive symptomatology and conditioning the subjects' day-to-day performance. However, despite the fact that anxiety is a frequent disorder in subjects diagnosed with ADHD, in the present study population, we observed that the average and high rates of state anxiety are much higher than those detected in other previously cited research.

In regard to sleep, $84.6 \%$ present medium-high alterations. If, under normal conditions, sleep disorders are very frequent in children with ADHD (appearing in $25-50 \%$ of cases and being five times more frequent than in healthy children [43]), it is to be expected that this frequency has been increased by an unprecedented situation such as the one experienced due to the outbreak of COVID-19. Therefore, to these results must be added the high levels of anxiety, which is related in a bidirectional way with sleep disorders [41]. Insufficient rest can have detrimental effects on cognitive processes, behavior, and mood: effects that are exacerbated in children and adolescents with neurodevelopmental disorders such as ADHD. In fact, recent research indicates that sleep disturbances may exacerbate the symptoms or be the cause of some of them, in combination with environmental and genetic factors [42-45], and an unprecedented situation such as that experienced during confinement by COVID-19, can be considered an environmental factor affecting sleep. In another study implemented during the confinement by Madrid [45], it is stated that this crisis is affecting the rest of children and adolescents, causing nightmares, night terrors, difficulty in falling asleep, or waking up several times at night, derived from the changes introduced into their lives by the pandemic that have disrupted their chronobiological clock.

With respect to executive functioning, around $91.4 \%$ show medium-high alterations. Research with adults suggests that anxiety is associated with poor control of executive attention [36]. The work of these authors examined executive attention in 860 children classified into three groups: anxiety disorders ( $n=67$, of which 43 had no specific phobia), $\operatorname{ADHD}(n=67)$, and controls $(n=726)$. Subjects with anxiety disorders did not show significant differences with respect to controls in executive attention tasks. However, the group of subjects that showed anxiety disorders without specific phobia obtained significantly higher scores compared to the groups that presented specific phobia and controls. The heterogeneity in executive attention among groups of children who present anxious traits seems to be similar to that observed in adults [73]. The ADHD group showed significantly higher results in the mentioned tasks with respect to the controls, when the effect of anxious symptoms was controlled, without finding large differences between ADHD with and without associated comorbidity (conduct disorder and oppositional defiant disorder). These results show high levels of cognitive dysfunction in ADHD that do not seem to be so pronounced in subjects diagnosed with anxiety disorders [36,70,71]. Along the same lines, a study conducted by Jarrett [74] examined the relationship between executive deficits, inattention, hyperactivity/impulsivity, and anxiety in adults, organized according to the diagnosis: ADHD and anxiety $(\mathrm{n}=36)$, ADHD without anxiety $(\mathrm{n}=35)$, anxiety without ADHD $(n=53)$, and controls $(n=32)$. The first structural equation model implied the 
latent factor of executive deficits as predictors of inattention, hyperactivity/impulsivity, and anxiety. Specifically, the group diagnosed with ADHD showed greater deficits in self-motivation and self-control than the anxious group. The subjects who presented ADHD and anxiety obtained scores that confirmed particularly pronounced problems in organization, problem solving, and emotional control compared to the ADHD group and the anxiety group (both groups showed no significant differences in these variables). The organization/problem-solving domain, measured in this study by the BAARS-IV scale, reflects the ability to organize thought and behavior quickly when the subject experiences unexpected events that require a specific solution. This construct has a relevant overlap with working memory (WM) and is consistent with suggestions made by other works, which support the incidence of higher WM deficits in subjects diagnosed with ADHD and anxiety $[40,47,67,73]$.

On the other hand, a second analysis was carried out with the intention of comparing the results obtained in the battery applied to both the confined clinical and confined nonclinical groups, showing that there are statistically significant differences in state anxiety $(p=0.004)$, sleep $(p=0.005)$, and executive functions $(p=0.001)$, with the results always being more negative for the clinical group. Likewise, after comparing the mean scores of the different scales used from a confined clinical group, a confined non-clinical group, and an unconfined group, as explained above, we found that the differences between the scores obtained are more unfavorable for the groups that have been in confinement, and even more so when those who have been confined presented a previous neurodevelopmental disorder such as ADHD. The COVID-19 pandemic may worsen pre-existing mental disorders and increase cases in children and adolescents, due to the public health crisis itself, social isolation, and economic recession [74]. All that confinement entails, such as school closures, interruptions in psycho-educational therapy, the absence of extracurricular activities, not being able to go out to play or play sports, etc., together with online schooling, parents working from home, an increase in constant negative news, and great uncertainty about how to approach the future has most probably favored the results of this study. As well as the findings of this study, the work of $[5,65,66,75]$, among others, also demonstrates that home confinement can have a negative impact on the physical and mental health of children and adolescents.

Finally, with regard to the results of the correlations between each group and the variables of anxiety, quality of sleep, and executive functions, it should be noted that there are moderate correlations for both the clinical and non-clinical groups, both of which are confined, with the exception of the correlation between anxiety and executive functions of the non-clinical confined group, which results in a weak correlation (0.286). This allows us to affirm that the higher the score in state anxiety, the worse the scores obtained in quality of sleep and in implementation of executive functions, with the difference that if the subject presents a neurodevelopmental disorder such as ADHD, anxiety affects more intensely the loss of cognitive skills linked to executive functions.

These results coincide with those of research such as that of Martel et al. [76], which determined that those who present better executive functions are more capable of processing emotional information, which leads them to better adaptation to changes in their environment and a lower risk of the appearance of psychopathologies. If we take into account that subjects diagnosed with ADHD have deficiencies in executive functions, it is logical to predict that the emotional management of anxiety will be more deficient than in cases that do not present this disorder, so the symptoms of anxiety will worsen and therefore the high cognitive functions such as executive functions will be the first to be impaired. Similarly, Garon and Waschbusch $[77,78]$ determined from their studies that subjects, who present a high level of anxiety and ADHD combined, are much less effective in making decisions that require the use of executive functions-a statement that would also be reinforced by our results.

In the mediation analysis carried out, we have found the influence of sex and age on the other variables measured in the sample with ADHD is non-existent. However, there 
are discrepancies between various authors when relating these variables to measurements of the mental health of children and adolescents during the pandemic. While Xie et al. [79] and Jiao et al. [80] agree with our findings, Zhou et al. [81] found greater symptoms of anxiety as age increased. Liu et al. [82], comparing the level of anxiety between elementary school students and university students, found the latter showed higher rates of anxiety, depression, and somatic symptoms. A study carried out with children from 3 to 18 years old [79] showed that children from 3 to 6 years old presented greater attachment and fear behaviors because their relatives contracted the disease and those from 6 to 18 years old had more symptoms of inattention and irritability. Regarding gender, some of the first studies published during the pandemic indicated that adolescent girls are the ones most likely to present anxiety and depressive symptoms [18,81]. Wang et al. [83] and Alvis et al. [84] endorse the above data by adding stress to the list of symptoms. On the other hand, Xie et al. [79] in a study carried out with a sample of children between 7 to 11 years old, did not find differences between sex. Ahmed et al. [85] extending the age range, did not find differences either.

Bayes and Ribes [86] argued the role of psychology in HIV-AIDS based on current evidence and various conceptual and theoretical models of experimental psychology. They considered that, regardless of the origin of the virus and its potential medical treatment, its acquisition and coping with it was a psychological process. Research on this subject has shown the relationship between prevention, adherence to treatment, and coping with different types of illness and the behavior of individuals. Urzúa et al. [64] state that in the case of the pandemic generated by COVID-19, the preventive measures offered include behavioral measures (regardless of whether the person is exposed to the virus, in quarantine, in a preventive situation of social distancing, or post-discharge). Similarly, psychological interventions have not been sufficiently documented; however, specialists consider that crisis interventions should be a measure for all affected groups [5], with the aim of minimizing psychological damage and providing assistance by trying to avoid subsequent problems such as post-traumatic stress. As Cortese et al. [17] published in the European guide for the management of ADHD during the pandemic by COVID-19, we consider it necessary that during periods of confinement, for the duration of the pandemic people with special needs arising from the manifestation of a disorder such as ADHD can enjoy the provision of medical-psychiatric, educational, and psychological services necessary for each of the cases, even if restricted to telephone or online.

As the main limitation of the study, we highlight the lack of a pretest or retest on the study sample: data which would allow comparing the degree to which the scores obtained are mainly generated by the current situation.

Derived from this study, three future investigations are projected that would complement the obtained results. Firstly, to carry out a new collection of information for the same sample once the current situation has been overcome and the subjects of the study have recovered part of the psychosocial habits that characterize their daily lives. Secondly, it would be very interesting to collect information about the cognitive capacity of the subjects that make up the sample in order to carry out a new study on the explanatory model, including this variable that is so decisive in explaining the development of executive functions. Thirdly, to develop intervention programs to prevent and/or treat the difficulties found in the subjects surveyed with the aim of minimizing as much as possible the consequences that confinement has generated both in their anxiety levels and quality of sleep, as well as in their executive functioning.

Author Contributions: I.N.-S., R.L., R.J.-R.d.M., B.C.-L., M.R.-F., M.S. collected and processed the experimental data, performed the analysis, drafted the manuscript, and designed the figures. All wrote the manuscript with support from I.N.-S. and R.L. All authors discussed the results and contributed to the final manuscript. I.N.-S. was one of the authors responsible for conceiving the idea of the study. He and R.L. were involved in planning and supervising the study. All authors discussed the results and contributed to the final manuscript. B.C.-L. and M.R.-F. were responsible for most of the technical aspects of the study and conducted the statistical analyses. All authors discussed the 
results and contributed to the final manuscript. All authors have read and agreed to the published version of the manuscript.

Funding: This research received no external funding.

Institutional Review Board Statement: The study was conducted according to the guidelines of the Declaration of Helsinki, and was carried out in accordance with the Ethics Committee and Vice-Rectorate for Research and Knowledge Transfer of the University of Alicante (UA-2020-05-12).

Informed Consent Statement: Informed consent was obtained from all subjects involved in the study.

Data Availability Statement: We provide a link where the data supporting the reported results can be found: https:/ / drive.google.com/drive/folders/1-WtcqwNjxrghdEpgbrV2f5IHu4RlBIYa?usp=sharing.

Acknowledgments: We extend sincere gratitude to all the families who participated in the study and the three anonymous referees for the time and effort dedicated to their reviews.

Conflicts of Interest: The authors declare no conflict of interest.

\section{References}

1. De España, G. Real Decreto 463/2020, de 14 de Marzo, Por El Que Se Declara El Estado de Alarma Para La Gestión de La Situación de Crisis Sanitaria Ocasionada Por El COVID-19; BOE-A-2020-3692); Agencia Estatal Boletín Oficial del Estado: Madrid, Spain, 2020.

2. Danese, A.; Smith, P.; Chitsabesan, P.; Dubicka, B. Child and adolescent mental health amidst emergencies and disasters. Br. J. Psychiatry 2020, 216, 159-162. [CrossRef]

3. Moya, M.; Willis, G.B.; Paez, D.; Pérez, J.A.; Gómez, Á.; Sabucedo-Cameselle, J.M.; Alzate, M.; Hur, D.; Rodríguez, A.; Extremera, N. La Psicología Social Ante El COVID19: Monográfico Del International. J. Soc. Psychol. Rev. Psicol. Soc. 2020. [CrossRef]

4. Xiao, H.; Zhang, Y.; Kong, D.; Li, S.; Yang, N. The effects of social support on sleep quality of medical staff treating patients with coronavirus disease 2019 (COVID-19) in January and February 2020 in China. Med. Sci. Monit. 2020, 26, 1-8.

5. Duan, L.; Zhu, G. Psychological interventions for people affected by the COVID-19 epidemic. Lancet Psychiatry 2020, 7, 300-302. [CrossRef]

6. Chen, Q.; Liang, M.; Li, Y.; Guo, J.; Fei, D.; Wang, L.; He, L.; Sheng, C.; Cai, Y.; Li, X.; et al. Mental health care for medical staff in China during the COVID-19 outbreak. Lancet Psychiatry 2020, 7, e15-e16. [CrossRef]

7. Yang, Y.; Li, W.; Zhang, Q.; Zhang, L.; Cheung, T.; Xiang, Y.-T. Mental health services for older adults in China during the COVID-19 outbreak. Lancet Psychiatry 2020, 7, e19. [CrossRef]

8. Cao, W.; Fang, Z.; Hou, G.; Han, M.; Xu, X.; Dong, J.; Zheng, J. The psychological impact of the COVID-19 epidemic on college students in China. Psychiatry Res. 2020, 287, 112934. [CrossRef] [PubMed]

9. Lavigne, R. Comparación de Tratamiento Farmacológico, Intervención Psicoeducativa y Tratamiento Combinado: La Importancia Del Sistema Ejecutivo y Sus Funciones; Universidad de Málaga: Málaga, Spain, 2009.

10. Vallejo-Slocker, L.; Fresneda, J.; A Vallejo, M. Psychological Wellbeing of Vulnerable Children During the COVID-19 Pandemic. Psicothema 2020, 32, 501-507.

11. De Miranda, D.M.; Athanasio, B.D.S.; Oliveira, A.C.S.; Simoes-E-Silva, A.C. How is COVID-19 pandemic impacting mental health of children and adolescents? Int. J. Disaster Risk Reduct. 2020, 51, 101845. [CrossRef] [PubMed]

12. Ramadhan, M.H.A.; Putri, A.K.; Melinda, D.; Habibah, U.; Fajriyah, U.N.; Aini, S.; Prananjaya, B.A.; Ikhsan, D.S. Children's Mental Health in the Time of COVID-19: How Things Stand and the Aftermath. Malays. J. Med Sci. 2020, 27, 196-201. [CrossRef] [PubMed]

13. Hidalgo, M.D.; Balluerka, N.; Gorostiaga, A.; Espada, J.P.; Santed, M.Á.; Padilla, J.L.; Gómez-Benito, J. The Psychological Consequences of COVID-19 and Lockdown in the Spanish Population: An Exploratory Sequential Design. Int. J. Environ. Res. Public Health 2020, 17, 8578. [CrossRef] [PubMed]

14. Morgül, E.; Kallitsoglou, A.; Essau, C.A. Psychological Effects of the COVID-19 Lockdown on Children and Families in the UK. Rev. Psicol. Clínica Con Niños Adolesc. 2020, 7, 42-48. [CrossRef]

15. Asmundson, G.J.; Taylor, S. How health anxiety influences responses to viral outbreaks like COVID-19: What all decision-makers, health authorities, and health care professionals need to know. J. Anxiety Disord. 2020, 71, 102211. [CrossRef] [PubMed]

16. Vahia, I.V.; Blazer, D.G.; Smith, G.S.; Karp, J.F.; Steffens, D.C.; Forester, B.P.; Tampi, R.; Agronin, M.; Jeste, D.V.; Reynolds, C.F. COVID-19, Mental Health and Aging: A Need for New Knowledge to Bridge Science and Service. Am. J. Geriatr. Psychiatry 2020, 28, 695-697. [CrossRef]

17. Cortese, S.; Asherson, P.; Sonuga-Barke, E.; Banaschewski, T.; Brandeis, D.; Buitelaar, J.; Coghill, D.; Daley, D.; Danckaerts, M.; Dittmann, R.W.; et al. ADHD management during the COVID-19 pandemic: Guidance from the European ADHD Guidelines Group. Lancet Child Adolesc. Health 2020, 4, 412-414. [CrossRef]

18. Chen, Z.; Tong, L.; Zhou, Y.; Hua, C.; Wang, W.; Fu, J.; Shu, Q.; Hong, L.; Xu, H.; Xu, Z.; et al. Childhood COVID-19: A multicentre retrospective study. Clin. Microbiol. Infect. 2020, 26, 1260.e1-1260.e4. [CrossRef]

19. Castellanos, F.X.; Marvasti, F.F.; Ducharme, J.L.; Walter, J.M.; Israel, M.E.; Krain, A.; Pavlovsky, C.; Hommer, D.W. Executive Function Oculomotor Tasks in Girls With ADHD. J. Am. Acad. Child Adolesc. Psychiatry 2000, 39, 644-650. [CrossRef] [PubMed] 
20. Capilla-González, A.; Fernández-González, S.; Campo, P.; Maestú, F.; Fernández-Lucas, A.; Mulas, F.; Ortiz, T. Magnetoencephalography in cognitive disorders involving frontal lobes. Revista de Neurología 2004, 39, 183-188.

21. Román, A.C.; Grande, D.D.R.; González, A.C.; Unturbe, F.M.; Alonso, T.O. Bases neurobiológicas de las dificultades de aprendizaje. Revista de Neurología 2006, 42, S171. [CrossRef]

22. Epstein, J.N.; Casey, B.; Tonev, S.T.; Davidson, M.C.; Reiss, A.L.; Garrett, A.; Hinshaw, S.P.; Greenhill, L.L.; Glover, G.; Shafritz, K.M.; et al. ADHD- and medication-related brain activation effects in concordantly affected parent-child dyads with ADHD. J. Child Psychol. Psychiatry 2007, 48, 899-913. [CrossRef]

23. Tirapu, J.; Muñoz, J.M.; Pelegrín, C. Funciones ejecutivas: Necesidad de una integración conceptual. Revista de Neurología 2002, 34 , 673. [CrossRef]

24. Lavigne, R.; Romero, J.F. Modelo Teórico Del Trastorno Por Déficit de Atención Con Hiperactividad I: Definición Operativa. Electron. J. Res. Educ. Psychol. 2010, 8, 1303-1338. [CrossRef]

25. Bausela, E.; Tirapu, J.; Cordero, P. Déficits ejecutivos y trastornos del neurodesarrollo en la infancia y en la adolescencia. Revista de Neurología 2019, 69, 461-469. [CrossRef] [PubMed]

26. Barkley, R.A.; Wasserstein, J. ADHD and The Nature of Self-Control. J. Cogn. Psychother. 2000, 14, 111-113. [CrossRef]

27. Colomer, C.; Miranda, A.; Herdoiza, P.; Presentación, M.J. Funciones ejecutivas y características estresantes de niños con trastorno por déficit de atención/hiperactividad: Influencia en los resultados durante la adolescencia. Revista de Neurología 2012, 54, 117-126. [CrossRef]

28. Humphreys, K.L.; Watts, E.L.; Dennis, E.L.; King, L.S.; Thompson, P.M.; Gotlib, I.H. Stressful Life Events, ADHD Symptoms, and Brain Structure in Early Adolescence. J. Abnorm. Child Psychol. 2018, 47, 421-432. [CrossRef] [PubMed]

29. Herreros, Ó.; Sánchez, F.; Ajoy, M.; Gracia, R. Evaluación de Niños y Adolescentes Con Trastorno Por Déficit de Atención Con Hiperactividad/Trastornos Hipercinéticos (TDAH). Rev. Psiquiatr. Infanto-Juv. 2002, 19, 199-214.

30. Gotlib, I.H.; Joormann, J. Cognition and Depression: Current Status and Future Directions. Annu. Rev. Clin. Psychol. 2010, 6, 285-312. [CrossRef]

31. Martínez, L.; Prada, E.; Satler, C.; Tavares, M.C.H.; Tomaz, C. Executive Dysfunctions: The Role in Attention Deficit Hyperactivity and Post-traumatic Stress Neuropsychiatric Disorders. Front. Psychol. 2016, 7, 1230. [CrossRef] [PubMed]

32. Pechtel, P.; Pizzagalli, D.A. Effects of early life stress on cognitive and affective function: An integrated review of human literature. Psychopharmacol. 2010, 214, 55-70. [CrossRef] [PubMed]

33. Hodgkins, P.; Setyawan, J.; Mitra, D.; Davis, K.; Quintero, J.; Fridman, M.; Shaw, M.; Harpin, V. Management of ADHD in children across Europe: Patient demographics, physician characteristics and treatment patterns. Eur. J. Nucl. Med. Mol. Imaging 2013, 172, 895-906. [CrossRef]

34. Guerrero, F. El Lado Oscuro Del TDAH En La Vida Adulta; Ediciones Aljibe: Málaga, Spain, 2014.

35. Sciberras, E.; Lycett, K.; Efron, D.; Mensah, F.; Gerner, B.; Hiscock, H. Anxiety in Children with Attention-Deficit/Hyperactivity Disorder. Pediatrics 2014, 133, 801-808. [CrossRef] [PubMed]

36. Mogg, K.; Salum, G.A.; Bradley, B.P.; Gadelha, A.; Pan, P.; Alvarenga, P.G.; Rohde, L.A.; Pine, D.S.; Manfro, G.G. Attention network functioning in children with anxiety disorders, attention-deficit/hyperactivity disorder and non-clinical anxiety. Psychol. Med. 2015, 45, 2633-2646. [CrossRef]

37. Rothbart, M.K.; Sheese, B.E.; Rueda, M.R.; Posner, M.I. Developing Mechanisms of Self-Regulation in Early Life. Emot. Rev. 2011, 3, 207-213. [CrossRef]

38. Eysenck, M.W.; Derakhshan, N.; Santos, R.; Calvo, M.G. Anxiety and cognitive performance: Attentional control theory. Emotion 2007, 7, 336-353. [CrossRef] [PubMed]

39. Posner, M.I.; Rothbart, M.K. Research on Attention Networks as a Model for the Integration of Psychological Science. Annu. Rev. Psychol. 2007, 58, 1-23. [CrossRef] [PubMed]

40. Jarrett, M.A. Attention-deficit/hyperactivity disorder (ADHD) symptoms, anxiety symptoms, and executive functioning in emerging adults. Psychol. Assess. 2016, 28, 245-250. [CrossRef] [PubMed]

41. Johnson, E.O.; Chilcoat, H.D.; Breslau, N. Trouble sleeping and anxiety/depression in childhood. Psychiatry Res. 2000, 94, 93-102. [CrossRef]

42. Valdizán, J.R. Trastornos generalizados del desarrollo y sueño. Revista de Neurología 2005, 41, S135. [CrossRef]

43. Cortese, S.; Faraone, S.V.; Konofal, E.; Lecendreux, M. Sleep in Children with Attention-Deficit/Hyperactivity Disorder: MetaAnalysis of Subjective and Objective Studies. J. Am. Acad. Child Adolesc. Psychiatry 2009, 48, 894-908. [CrossRef] [PubMed]

44. Mulas, F.; Rojas, M.; Gandía, R. Sueño En Los Trastornos Del Neurodesarrollo, Déficit de Atención e Hiperactividad y En El Espectro Autista. Med. B. Aires. 2019, 79, 33-36.

45. Madrid, J.A. Los Trastornos Del Sueño En Niños Pueden Provocar Problemas de Memoria, Sobrepeso y Depresión. El País. 2020. Available online: https:/ /elpais.com/elpais/2020/05/25/mamas_papas/1590428224_998413.html (accessed on 14 February 2021).

46. National Child Traumatic Stress Network. Guía de Ayuda Para Padres y Cuidadores Para Ayudar a Las Familias a Enfrentar La Enfermedad Coronavirus 2019 (COVID-19). April 2020. Available online: https://www.nctsn.org/sites/default/files/ resources/fact-sheet/parent_caregiver_guide_to_helping_families_cope_with_the_coronavirus_disease_2019-sp.pdf (accessed on 14 February 2021).

47. Lavigne, R.; Costa, B.; Juárez-Ruíz de Mier, R.; Real, M.; Sánchez-Muñoz de León, M.; Navarro, I. Consequences of Covid-19 Confinement on Anxiety, Sleep and Executive Functions of Children and Adolescents in Spain. Front. Psychol. 2021, $12,1-11$. 
48. Daley, P. We Face a Pandemic of Mental Health Disorders. Those Who Do It Hardest Need Our Support. Guard. 24 March 2021. Available online: https:/ / www.theguardian.com/commentisfree/2020/mar/25/we-face-a-pandemic-of-mental-healthdisorders-those-who-do-it-hardest-need-our-support (accessed on 14 February 2021).

49. Ezpeleta, D.; García-Azorín, D. Manual COVID-19 Para El Neurólogo General; Ediciones SEN: Madrid, Spain, 2020.

50. Wright, A.; Salazar, A.; Mirica, M.; Volk, L.A.; Schiff, G.D. The Invisible Epidemic: Neglected Chronic Disease Management During COVID-19. J. Gen. Intern. Med. 2020, 35, 2816-2817. [CrossRef]

51. Ato, M.; López-García, J.J.; Benavente, A. Un sistema de clasificación de los diseños de investigación en psicología. Anales de Psicología 2013, 29, 1038-1059. [CrossRef]

52. Spielberger, C.D.; Edwards, C.D.; Montuori, J.; Lushene, R. Manual for the State-Trait Inventory for Children; Mind Garden, Inc.: Menlo Park, CA, USA, 1973.

53. Owens, J.A.; Dalzell, V. Use of the 'BEARS' sleep screening tool in a pediatric residents' continuity clinic: A pilot study. Sleep Med. 2005, 6, 63-69. [CrossRef] [PubMed]

54. Vélez, R.R.; Zamora, L.H.; Bautista, J.E.C.; Calderón, E.G.C. Confiabilidad y Validez Del Cuestionario de Trastornos de Sueño BEARS En Niños y Adolescentes Escolares de Bogotá, DC, Colombia: Estudio FUPRECOL. Retos Nuevas Tend. Educ. Física Deporte Recreación. 2018, 34, 89-93.

55. Barkley, R.A. Barkley Deficits in Executive Functioning Scale-Children and Adolescents (BDEFS-CA); Guilford Press: New York, NY, USA, 2012.

56. World Medical Association. World medical association declaration of Helsinki: Ethical principles for medical research involving human subjects. JAMA 2013, 310, 2191-2194. [CrossRef]

57. Field, A. Discovering Statistics Using SPSS:(And Sex and Drugs and Rock'n'Roll); Sage: Thousand Oaks, CA, USA, 2009.

58. Hayes, A.F. Introduction to Mediation, Moderation, and Conditional Process Analysis: A Regression-Based Approach; Guilford Press: New York, NY, USA, 2017.

59. Preacher, K.J.; Hayes, A.F. SPSS and SAS procedures for estimating indirect effects in simple mediation models. Behav. Res. Methods Instrum. Comput. 2004, 36, 717-731. [CrossRef]

60. Preacher, K.J.; Rucker, D.D.; Hayes, A.F. Addressing Moderated Mediation Hypotheses: Theory, Methods, and Prescriptions. Multivar. Behav. Res. 2007, 42, 185-227. [CrossRef]

61. Preacher, K.J.; Hayes, A.F. Asymptotic and resampling strategies for assessing and comparing indirect effects in multiple mediator models. Behav. Res. Methods 2008, 40, 879-891. [CrossRef]

62. Cohen, J. The Effect Size Index: D. Statistical Power Analysis for the Behavioral Sciences 2; Lawrence Erlbaum, Associates, Inc.: London, UK, 1988.

63. Hernández Lalinde, J.D.; Espinosa Castro, J.F.; Peñaloza Tarazona, M.E.; Fernández González, J.E.; Chacón Rangel, J.G.; Toloza Sierra, C.A.; Arenas Torrado, M.K.; Carrillo Sierra, S.M.; Bermúdez Pirela, V.J. Sobre El Uso Adecuado Del Coeficiente de Correlación de Pearson: Definición, Propiedades y Suposiciones. Archivos Venezolanos de Farmacología y Terapéutica 2018, 37, 587-595.

64. Urzúa, A.; Vera-Villarroel, P.; Caqueo-Urízar, A.; Polanco-Carrasco, R. La Psicología en la prevención y manejo del COVID-19. Aportes desde la evidencia inicial. Terapia Psicológica 2020, 38, 103-118. [CrossRef]

65. Brazendale, K.; Beets, M.W.; Weaver, R.G.; Chandler, J.L.; Randel, A.B.; Turner-McGrievy, G.M.; Moore, J.B.; Huberty, J.L.; Ward, D.S. Children's Moderate to Vigorous Physical Activity Attending Summer Day Camps. Am. J. Prev. Med. 2017, 53, 78-84. [CrossRef] [PubMed]

66. Brooks, S.K.; Webster, R.K.; Smith, L.E.; Woodland, L.; Wessely, S.; Greenberg, N.; Rubin, G.J. The Psychological Impact of Quarantine and How to Reduce It: Rapid Review of the Evidence. Lancet 2020, 395, 912-920. [CrossRef]

67. Zhang, J.; Shuai, L.; Yu, H.; Wang, Z.; Qiu, M.; Lu, L.; Cao, X.; Xia, W.; Wang, Y.; Chen, R. Acute stress, behavioural symptoms and mood states among school-age children with attention-deficit/hyperactive disorder during the COVID-19 outbreak. Asian J. Psychiatry 2020, 51, 102077. [CrossRef]

68. Xie, X.; Xie, J. Parental phubbing accelerates depression in late childhood and adolescence: A two-path model. J. Adolesc. 2020, 78, 43-52. [CrossRef]

69. Power, T.J.; Costigan, T.E.; Eiraldi, R.B.; Leff, S.S. Variations in Anxiety and Depression as a Function of ADHD Subtypes Defined by DSM-IV: Do Subtype Differences Exist or Not? J. Abnorm. Child Psychol 2004, 32, 27-37. [CrossRef] [PubMed]

70. Lee, J. Mental health effects of school closures during COVID-19. Lancet Child Adolesc. Health 2020, 4, 421. [CrossRef]

71. González-Castro, P.; Rodríguez, C.; Cueli, M.; García, T.; Alvarez-García, D. State, trait anxiety and selective attention differences in Attention Deficit Hyperactivity Disorder (ADHD) subtypes. Int. J. Clin. Health Psychol. 2015, 15, 105-112. [CrossRef]

72. Sadeh, N.; Bredemeier, K. Individual differences at high perceptual load: The relation between trait anxiety and selective attention. Cogn. Emot. 2011, 25, 747-755. [CrossRef]

73. Airaksinen, E.; Larsson, M.; Forsell, Y. Neuropsychological functions in anxiety disorders in population-based samples: Evidence of episodic memory dysfunction. J. Psychiatr. Res. 2005, 39, 207-214. [CrossRef] [PubMed]

74. Jarrett, M.A.; Ollendick, T.H. Treatment of comorbid attention-deficit/hyperactivity disorder and anxiety in children: A multiple baseline design analysis. J. Consult. Clin. Psychol. 2012, 80, 239-244. [CrossRef] [PubMed]

75. Golberstein, E.; Wen, H.; Miller, B.F. Coronavirus Disease 2019 (COVID-19) and Mental Health for Children and Adolescents. JAMA Pediatr. 2020, 174, 819. [CrossRef] 
76. Hong, H.; Wang, Y.; Chung, H.-T.; Chen, C.-J. Clinical characteristics of novel coronavirus disease 2019 (COVID-19) in newborns, infants and children. Pediatr. Neonatol. 2020, 61, 131-132. [CrossRef]

77. Martel, M.M.; Nigg, J.T.; Wong, M.M.; Fitzgerald, H.E.; Jester, J.M.; Puttler, L.I.; Glass, J.M.; Adams, K.M.; Zucker, R.A. Childhood and adolescent resiliency, regulation, and executive functioning in relation to adolescent problems and competence in a high-risk sample. Dev. Psychopathol. 2007, 19, 541-563. [CrossRef] [PubMed]

78. Garon, N.; Moore, C.; Waschbusch, D.A. Decision Making in Children with ADHD Only, ADHD-Anxious/Depressed, and Control Children Using a Child Version of the Iowa Gambling Task. J. Atten. Disord. 2006, 9, 607-619. [CrossRef]

79. Xie, X.; Xue, Q.; Zhou, Y.; Zhu, K.; Liu, Q.; Zhang, J.; Song, R. Mental Health Status Among Children in Home Confinement During the Coronavirus Disease 2019 Outbreak in Hubei Province, China. JAMA Pediatr. 2020, 174, 898. [CrossRef] [PubMed]

80. Jiao, W.Y.; Na Wang, L.; Liu, J.; Fang, S.F.; Jiao, F.Y.; Pettoello-Mantovani, M.; Somekh, E. Behavioral and Emotional Disorders in Children during the COVID-19 Epidemic. J. Pediatr. 2020, 221, 264-266.e1. [CrossRef] [PubMed]

81. Zhou, Y.; Zhou, Y.; Song, Y.; Ren, L.; Ng, C.H.; Xiang, Y.-T.; Tang, Y. Tackling the mental health burden of frontline healthcare staff in the COVID-19 pandemic: China's experiences. Psychol. Med. 2020, 1-2. [CrossRef]

82. Liu, S.; Liu, Y.; Liu, Y. Somatic symptoms and concern regarding COVID-19 among Chinese college and primary school students: A cross-sectional survey. Psychiatry Res. 2020, 289, 113070. [CrossRef]

83. Wang, C.; Pan, R.; Wan, X.; Tan, Y.; Xu, L.; Ho, C.S.; Ho, R.C. Immediate Psychological Responses and Associated Factors during the Initial Stage of the 2019 Coronavirus Disease (COVID-19) Epidemic among the General Population in China. Int. J. Environ. Res. Public Health 2020, 17, 1729. [CrossRef] [PubMed]

84. Alvis, L.; Shook, N.; Oosterhoff, B. Adolescents' Prosocial Experiences during the Covid-19 Pandemic: Associations with Mental Health and Community Attachments. PsyArXiv 2020, 1-25. Available online: https:/ / psyarxiv.com/2s73n\# (accessed on 14 February 2021). [CrossRef]

85. Ahmed, M.Z.; Ahmed, O.; Aibao, Z.; Hanbin, S.; Siyu, L.; Ahmad, A. Epidemic of COVID-19 in China and associated Psychological Problems. Asian J. Psychiatry 2020, 51, 102092. [CrossRef] [PubMed]

86. Bayés, R.; Ribes, E. Un Modelo Psicológico de Enfermedad: Su Aplicación al Caso Del SIDA. In J. A. Piña (Comp.), Psicología y Salud: Aportes Del Análisis de La Conducta; Unison: Hermosillo, México, 1992. 